\title{
The influence of ferrous ions on the efficiency of aqueous photocatalytic oxidation of 2-ethoxy ethanol
}

\author{
D. Klauson ${ }^{1}$ and S. Preis ${ }^{2, \dagger}$ \\ ${ }^{1}$ Department of Chemical Engineering, Tallinn University of Technology, Ehitajate tee 5, Tallinn 19086, Estonia \\ ${ }^{2}$ Department of Chemical Technology, Lappeenranta University of Technology, P.O. Box 20, \\ FIN-53851, Lappeenranta, Finland
}

\begin{abstract}
The complex influence of ferrous ions on the efficiency of aqueous photocatalytic oxidation (PCO) of 2-ethoxyethanol (2-EE) was examined. A drastic efficiency increase at lower concentrations of ferrous ions was observed to change to a sharp decrease at higher concentrations. An explanation was proposed for the observed phenomena based on the low sensitivity of the pollutant towards radical-oxidation reactions and the competitive adsorption of metallic ions and 2-EE on the $\mathrm{TiO}_{2}$ surface.
\end{abstract}

\section{INTRODUCTION}

2-Ethoxyethanol (2-EE, $\left.\mathrm{CH}_{3}-\mathrm{CH}_{2}-\mathrm{O}-\mathrm{CH}_{2}-\mathrm{CH}_{2}-\mathrm{OH}\right)$ is used as a solvent, a de-icing agent for runways and aircrafts, and an antifreeze jet fuel additive. This substance is often present in groundwater as a result of leakage, accidental spillages and uncontrolled disposal of fuels and de-icing liquids. It has negative effects on the kidneys, respiratory, and reproductive systems, and also acts as a depressant of the central nervous system [1]. The de-icing agents have been proven by earlier studies to be refractory against biodegradation and thus they accumulate and remain intact in groundwater for long times [2].

The photocatalytic oxidation (PCO) of organic pollutants is based on the action of positively charged holes on the semiconductor surface [3]. However, the holes may recombine rapidly with conduction band electrons, decreasing the PCO efficiency. Prolongation of the holes' lifetime should, therefore, increase the efficiency of PCO. For this purpose, multivalent metal ions may be added to the treated solutions, or, more precisely, to the photocatalyst surface, to scavenge electrons at the surface of the titanium dioxide, thus preventing electron-hole recombination and improving the oxidation performance.

This paper analyses the influence of ferrous ion additives on the PCO of 2-EE. Several previous studies [4-6] have reported higher PCO rates following the addition of small amounts of ferrous ions. Sucrose, carboxylic acids and textile azo dye were the organic pollutants in these studies. However, higher concentrations of ferrous ion reduced the decomposition rate significantly. A similar trend was observed with other multivalent metals influencing PCO of phenol and sucrose $[7,8]$. Our previous studies [9] showed the positive

${ }^{\dagger}$ E-mail: Sergei.Preis@lut.fi role of ferrous ions at low concentrations in the efficiency of PCO of methyl tert-butyl ether (MTBE), although the PCO experiments with 2-EE, carried out in the same range of concentrations of $\mathrm{Fe}^{2+}$, indicated only a negative effect of iron ions. The results of more detailed investigation, given here, extend the knowledge of the influence of iron ions on pollutants of various types and show the complex character of the dependence of the PCO efficiency on the concentration of iron ions.

\section{EXPERIMENTAL SECTION}

Two 200-mL simple batch reactors with inner diameter $100 \mathrm{~mm}$ (evaporation dishes), aperture $40 \mathrm{~m}^{2} \mathrm{~m}^{-3}$, thermostatted at $20 \pm 1{ }^{\circ} \mathrm{C}$ and mechanically agitated with magnetic stirrers were used in the PCO experiments: the reactor used for the PCO was called "active" and the other, containing no photocatalyst, was called "reference". Both reactors were exposed to identical experimental conditions. The samples from the active reactor were compared to the reference samples to avoid complications caused by water evaporation. A UV-light source, Phillips TLD 15 W/05 low-pressure luminescent mercury UV-lamp with the emission maximum at 360-nm, was positioned horizontally over the reactors, providing irradiance of about $0.7 \mathrm{~mW} \mathrm{~cm}^{-2}$ measured by the optical radiometer UVX at a distance corresponding to the level of the free surface of the reactor.

The experiments were conducted with synthetic solutions at a concentration of $300 \mathrm{mg} \mathrm{L}^{-1}$ of 2-EE. The concentration of 2-EE was chosen to be consistent with its presence in polluted groundwater and experimental conditions applied previously [9]. All experiments were carried out at $\mathrm{pH} 3.0$, adjusted with sulphuric acid. The treatment time, $24 \mathrm{~h}$, was chosen to reduce 
the concentration of 2-EE below $50 \%$ of the residual concentration and was used in calculations of the process efficiency $E$ (see eq. (1)). All the experiments were carried out three times under identical conditions. The average deviation of data in parallel experiments did not exceed $5 \%$.

The experiments were performed using titanium dioxide as Degussa P25. Slurry at $1 \mathrm{~g} \mathrm{~L}^{-1}$ was used as a suspended catalyst option. The supported catalyst option was $\mathrm{TiO}_{2}$ attached to buoyant hollow glass microspheres and to the surface of the glass plates. The hollow glass micro-spheres used in this study had an average diameter of 60 to $70 \mu \mathrm{m}$ and a density $0.27 \mathrm{~g} \mathrm{~cm}^{-3}$ (the product of LP-ImpEx, Estonia). Titanium dioxide was attached to the surface of the micro-beads by the thermal method [10]: equal volumes of dry microspheres and aqueous suspension of titanium dioxide with a concentration of $1 \mathrm{~g} \mathrm{~L}^{-1}$ were mixed by stirring and sonication for $30 \mathrm{~min}$. The micro-spheres were then separated from the mixture by filtration with a membrane filter, heated to dryness at $120^{\circ} \mathrm{C}$ and calcinated at a temperature of $300^{\circ} \mathrm{C}$ for $4 \mathrm{~h}$. This procedure was repeated six times, which was found to be the optimum number of attachment operations [11]. Analogously, $\mathrm{TiO}_{2}$ was attached to the surface of the glass plates (one side) in approximately equal amounts either by multiple submerging of the plates in the $\mathrm{TiO}_{2}$ suspension with subsequent drying after each submersion, or by spraying the $\mathrm{TiO}_{2}$ suspension over the surface of the plates and drying. $\mathrm{TiO}_{2}$ attached to glass plates, submerged horizontally in the solution to be treated at a depth from 5 to $10 \mathrm{~mm}$, was used in the PCO experiments. Since 2-EE does not absorb UV light at $360 \mathrm{~nm}$, the depth of the submersion was not important within the indicated limits. This was confirmed by specially conducted experiments.

The decrease in the pollutant concentration was determined for 2-EE from the decrease in chemical oxygen demand (COD), measured by a standard method [12].

Adsorption experiments for oxygenated hydrocarbons and ferrous ion, introduced as sulphate, on the $\mathrm{TiO}_{2}$ surface were conducted in the dark in closed flasks equipped with magnetic stirrers, thermostatted at $20 \pm$ $1{ }^{\circ} \mathrm{C}$ and adjusted to $\mathrm{pH}$ 3.0. The amount of substances adsorbed was derived from the batch mass balance: the concentration of the dissolved substance was determined before and after adsorption. The points of the isotherms are the average of three experimental sets. The concentrations of iron ions were determined by a photometric phenantrolin method described in [12].

The PCO by-products of 2-EE, mainly carbonic acids, were qualitatively determined by the methods described in [13]. $200 \mathrm{mg}$ of resorcinol was added to $5 \mathrm{ml}$ of the sample in a test-tube. After the resorcinol had dissolved, $10 \mathrm{ml}$ of concentrated sulphuric acid was carefully inserted into the bottom of the test-tube. The coloured rings corresponding to carbonic acids ap- peared in the following sequence: the blue ring indicating oxalic acid appeared at the liquids' interface, the red ring below the blue one indicated glycolic acid, the orange ring above the blue one corresponds to formic acid. The rings were observed distinctively and repeatedly with both synthetic solutions of the acids and the samples of PCO treated 2-EE solutions. Oxalic acid was also separated from the sample as calcium oxalate and quantitatively determined by means of titration with potassium permanganate. Acetic acid was qualitatively determined as red crystals of iron (III) acetate precipitated as a result of addition of iron (III) chloride to the sample. These identifications were available only in the absence of iron ions in the treated samples, i.e. when the samples were treated without iron ions added.

\section{RESULTS AND DISCUSSION}

The performance of PCO with artificial radiation sources was characterised by the process efficiency $E$. The efficiency $E$ is defined as the decrease in the amount of pollutant divided by the amount of energy reaching the surface of the treated sample (eq. (1)). The efficiency values were calculated after a period of time equal to the treatment time $(24 \mathrm{~h})$

$$
E=\frac{\Delta c \cdot V \cdot 1000}{I \cdot s \cdot t}
$$

where $E$-PCO efficiency, $\mathrm{mg} \mathrm{W}^{-1} \mathrm{~h}^{-1} ; \Delta c$-the decrease in the concentration of the pollutant, $\mathrm{mg} \mathrm{O}_{2} \mathrm{~L}^{-1}$ for COD of 2-EE; $V$-the volume of the sample to be treated, L; $I$-irradiance, $\mathrm{mW} \mathrm{cm}^{-2} ; s$-irradiated area, $\mathrm{cm}^{2} ; t$-treatment time, $\mathrm{h}$.

Both ferrous and ferric ions were tested in the experiments. Sulphate was chosen as the counter-ion due to its low inhibitive effect on PCO efficiency, observed with 2-EE in [9]. The results of the experiments are shown in Figure 1. One can see a similar trend in the dependence of PCO performance on the concentrations of both ionic species. Ferric ions were seen to have the same effect as ferrous ions, which may be explained with a dynamic equilibrium established between ferrous and ferric ions at the UV-irradiated $\mathrm{TiO}_{2}$ surface and, probably, in its closest vicinity, as described in [14].

Ferrous and ferric ions appeared to play a significant role in PCO of 2-EE. The addition of small amounts of $\mathrm{Fe}^{2+/ 3+}$-ion, up to $0.09 \mathrm{mM}$, resulted in a drastic, up to $60 \%$, increase in the process efficiency (Figure 1). With further increase in the concentration of $\mathrm{Fe}^{2+/ 3+}$, the PCO efficiency decreased dramatically. Therefore, the experiments were conducted with ferrous ions the characterisation of which at $t=0$ and in aqueous solution was far simpler. During the PCO process, the dynamic equilibrium $\mathrm{Fe}^{2+} / \mathrm{Fe}^{3+}$ took place very fast.

A similar dependency pattern, in which the PCO efficiency of 2-EE had its maximum with a $\mathrm{Fe}^{2+/ 3+}$ 


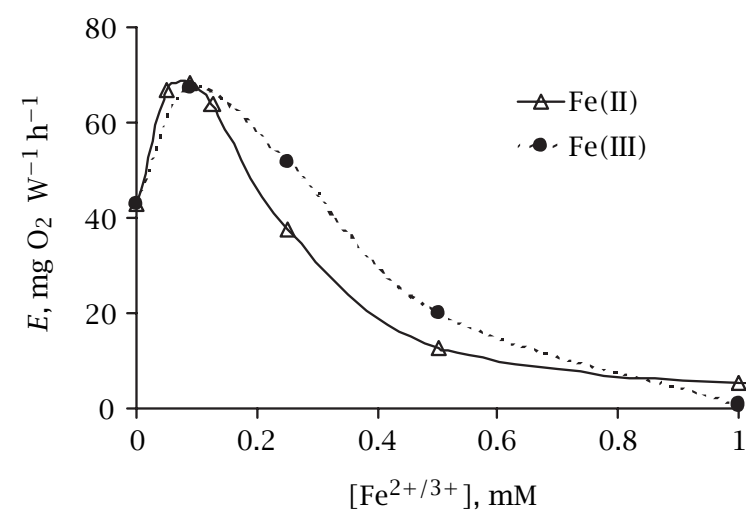

Figure 1. The efficiency of PCO of 2-ethoxyethanol in $\mathrm{TiO}_{2}$ slurry vs. concentration of $\mathrm{Fe}^{2+}(\Delta)$ and $\mathrm{Fe}^{3+}(\bullet)$ ions at pH 3.0.

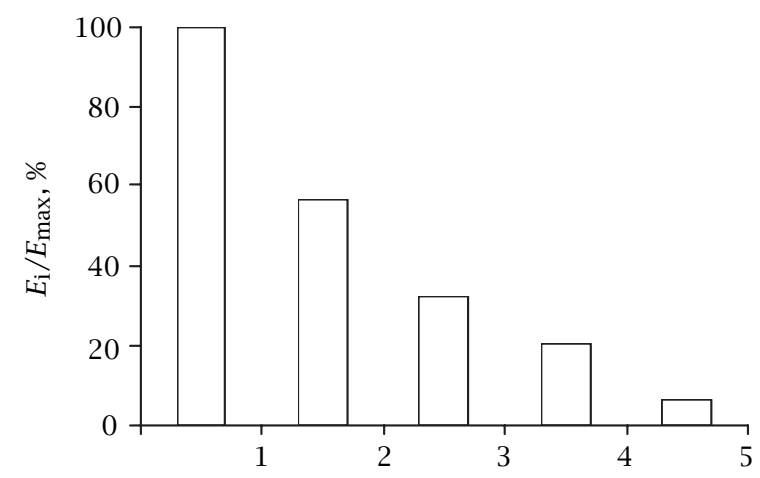

Figure 2. Efficiency of PCO of 2-ethoxyethanol at $0.09 \mathrm{mM}$ of $\mathrm{Fe}^{2+}$ with $\mathrm{TiO}_{2}$ application modes: $1-\mathrm{TiO}_{2}$ Degussa $\mathrm{P} 25$ suspension $\left(1 \mathrm{~g} \mathrm{~L}^{-1}\right) ; 2-\mathrm{TiO}_{2}$ sprayed on the glass plate, $0.6 \mathrm{mg} \mathrm{cm}^{-2} ; 3-\mathrm{TiO}_{2}$ settled at the glass plate, $0.7 \mathrm{mg} \mathrm{cm}^{-2}$; $4-\mathrm{TiO}_{2}$ attached to hollow glass micro-spheres, the amount of buoyant catalyst in the reactor $50 \mathrm{~g} \mathrm{~m}^{-2} ; 5$-same as 4 at $25 \mathrm{~g} \mathrm{~m}^{-2}$.

concentration of $0.09 \mathrm{mM}$, was observed for $\mathrm{TiO}_{2}$ attached to the glass plates, although the absolute values of the PCO efficiency were about 40 to $70 \%$ lower than with the $\mathrm{TiO}_{2}$ slurry. Buoyant micro-beads with attached $\mathrm{TiO}_{2}$ were the least effective (Figure 2).

Figure 2 shows that the difference in the procedure of $\mathrm{TiO}_{2}$ attachment to the glass plates affects the PCO efficiency: attachment by spraying appeared to lead to more effective PCO. This may not be explained by the difference in the mass of $\mathrm{TiO}_{2}$, since the attached mass was virtually the same, but is most probably due to uneven relief and porosity of the catalyst surface and, thus, a larger contact surface resulting from nonuniform spray attachment.

Methyl tert-butyl ether showed a trend somewhat similar to 2-EE, observed in our previous work: the drastic increase in PCO efficiency at smaller concentrations

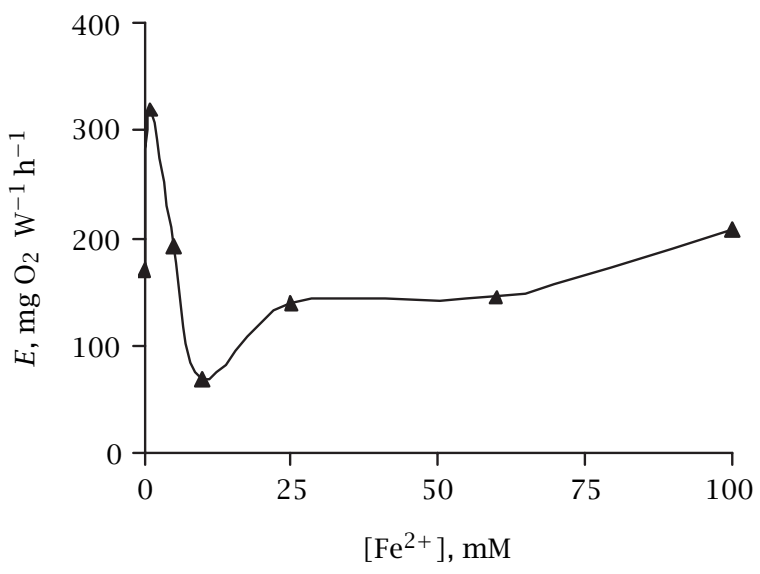

Figure 3. The efficiency of PCO of MTBE in $\mathrm{TiO}_{2}$ slurry vs. concentration of $\mathrm{Fe}^{2+}$-ions at $\mathrm{pH} 3.0$.

of $\mathrm{Fe}^{2+}$-ions was followed by a decrease with further addition of ferrous ions (Figure 3) [9]. However, the maximum efficiency for MTBE was observed at the $\mathrm{Fe}^{2+}$ concentration of $1 \mathrm{mM}$, which is about ten times bigger than that for 2-EE. A further increase in the concentration of $\mathrm{Fe}^{2+}$-ions resulted in a gradual increase of PCO efficiency, which was not observed with 2-EE. This may be explained by the difference in the PCO mechanism of these two substances and their different adsorption properties at the surface of titanium dioxide.

The difference in the behaviour of 2-EE and MTBE can be explained by a dual mechanism [3]: (1) the adsorption of the pollutant by the surface of the titanium dioxide is followed by a direct subtraction of the pollutant's electrons, i.e. oxidation, with positively charged holes; (2) oxidation with hydroxyl radicals takes place at the catalyst surface or in its vicinity. Both reactions proceed simultaneously, although positively charged holes have an oxidation potential about 1.25 times bigger than $\mathrm{OH}$-radicals [15]. Which mechanism dominates in PCO depends on the chemical and adsorption properties of the pollutant.

The promotion of the $\mathrm{OH}$-radical was less effective in oxidation of ethylene glycol derivatives $[16,17]$. The increasing PCO efficiency for 2-EE with the addition of ferrous ions in small, below $0.09 \mathrm{mM}$, concentrations may then be explained by the partial occupation of adsorption sites with $\mathrm{Fe}^{2+}$-ions, overpowered, however, with the electron scavenging by iron ions, extending the lifetime and thus the oxidation performance of the positively charged holes. A further increase in the concentration of metallic ions results in the blockage of adsorption sites with a resultant drastic decrease in PCO efficiency. The formation of hydroxyl radicals has little effect on the overall oxidation rate.

Methyl tert-butyl ether is less resistant towards oxidation with a hydroxyl radical. For example, oxidation methods, such as ozonation, exhibited poor 


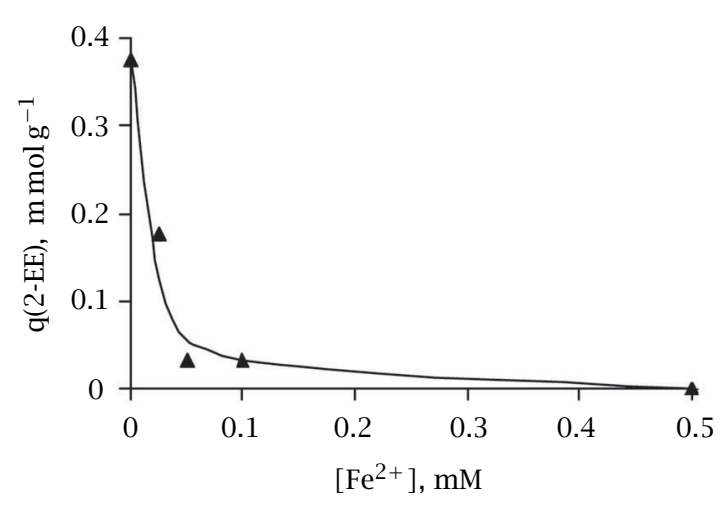

Figure 4. The surface concentration of 2 -EE on $\mathrm{TiO}_{2}$ versus $\mathrm{Fe}^{2+}$-ions equilibrium concentration at $\mathrm{pH} 3.0\left(20^{\circ} \mathrm{C}\right)$.

performance in the abatement of MTBE, although introduction of $\mathrm{OH}$-radical promoters significantly enhanced oxidation [18]. This makes both PCO mechanisms effective in PCO of MTBE. Small concentrations of ferrous ions therefore enhance the direct oxidation of MTBE with positively charged holes, and also the formation of $\mathrm{OH}$-radicals. Radical oxidation reactions contribute to the overall oxidation rate successfully until a certain concentration of metallic ions, $1 \mathrm{mM}$, is achieved (Figure 3). Above this concentration, the formation of $\mathrm{OH}$-radicals is probably obstructed by a "short-circuit" phenomenon, described in [4]: the blockage of the $\mathrm{TiO}_{2}$ adsorption sites with ferrous ions results in reduced generation of $\mathrm{OH}$-radicals. The increase of the PCO efficiency with further increasing ferrous ion concentration may be explained by increased $\mathrm{OH}$-radicals formation in the bulk solution initiated by the UV-irradiated $\mathrm{Fe}^{2+}$-ions. It was also observed that MTBE oxidized to some extent under UVirradiation in aqueous solutions containing $\mathrm{Fe}^{2+}$-ions with no $\mathrm{TiO}_{2}$ present, although this reaction was beyond the scope of the present paper. In the $\mathrm{TiO}_{2}$-free experiments the oxidation rate increased with increasing concentration of $\mathrm{Fe}^{2+}$-ions. The authors presume that oxidation of MTBE with UV-irradiated $\mathrm{Fe}^{2+}$ may be enhanced in the presence of $\mathrm{TiO}_{2}$. However, further experimental studies are necessary to confirm this statement.

To support the hypothesis concerning the role of ferrous ions in PCO performance determined by the adsorption properties and the sensitivity of the target compounds towards radical attacks, the impact of the $\mathrm{Fe}^{2+}$-ions on the adsorption of a pollutant by $\mathrm{TiO}_{2}$ was studied in a series of adsorption experiments. The ferrous ions content dependency of adsorption of 2-EE from a solution with an equilibrium concentration of 2-EE $300 \mathrm{mg} \mathrm{L}^{-1}$ by the $\mathrm{TiO}_{2}$ surface was determined experimentally. As one can see from Figure 4, the surface concentration of 2-EE steadily decreased within the

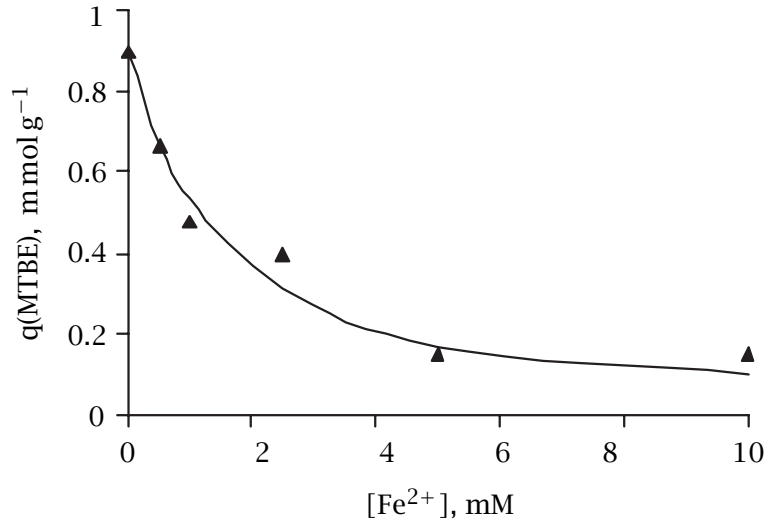

Figure 5. The surface concentration of MTBE on $\mathrm{TiO}_{2}$ versus $\mathrm{Fe}^{2+}$-ions concentration at $\mathrm{pH} 3.0\left(20^{\circ} \mathrm{C}\right)$.

$\mathrm{Fe}^{2+}$-ions equilibrium concentration range attributable to the peak zone of the PCO efficiency (Figure 1).

An analogous dependence of the equilibrium surface concentration of MTBE was also observed: the MTBE surface concentration in equilibrium with an MTBE solution of $100 \mathrm{mgL}^{-1}$ decreased from $0.9 \mathrm{mmol} \mathrm{g}^{-1}$ at zero concentration of $\mathrm{Fe}^{2+}$-ions to $0.5 \mathrm{mmolg}^{-1}$ at $1 \mathrm{mM}$ and $0.1 \mathrm{mmol} \mathrm{g}^{-1}$ at $10 \mathrm{mM}$ of $\mathrm{Fe}^{2+}$-ions (Figure 5). This explains the difference between the critical concentration values of $\mathrm{Fe}^{2+}$-ions for 2-EE and MTBE: the adsorption of MTBE was less affected by the presence of $\mathrm{Fe}^{2+}$-ions than 2-EE.

The last observation may be explained by differences in adsorption of 2-EE and MTBE. The carbonic acids determined qualitatively as PCO products of 2EE include oxalic, acetic, formic and glycolic acids. The possible route of the reactions is outlined in Figure 6. The presence of acetic and especially glycolic acids among the oxidation by-products indicate the adsorption of 2-EE with its etheric oxygen and, therefore, electrophilic attack of positively charged holes to the etheric bond. This results in fracture of the 2-EE molecule into two fragments, the acetic and glycolic acids (reaction A). The formation of oxalic acid appears to be possible only when both oxygen atoms in the 2EE molecules are adsorbed on the $\mathrm{TiO}_{2}$ surface and are under simultaneous attack of positively charged holes (reaction B). A further possible precursor of oxalic acid is glycolic acid, when the alcoholic group is oxidised (reaction C). Hypothetically, acetic acid may also be a product of 2-EE stepwise oxidation starting from the alcohol group only (reaction D) with formic acid as a product of the last reaction. The ethoxy carbonic acids were not identified and were only shown as hypothetical byproducts in rectangular brackets. Further oxidation of reactive by-products, such as formic acid also observed in samples, may proceed with OH-radicals formed at the $\mathrm{TiO}_{2}$ surface, although their formation may be 


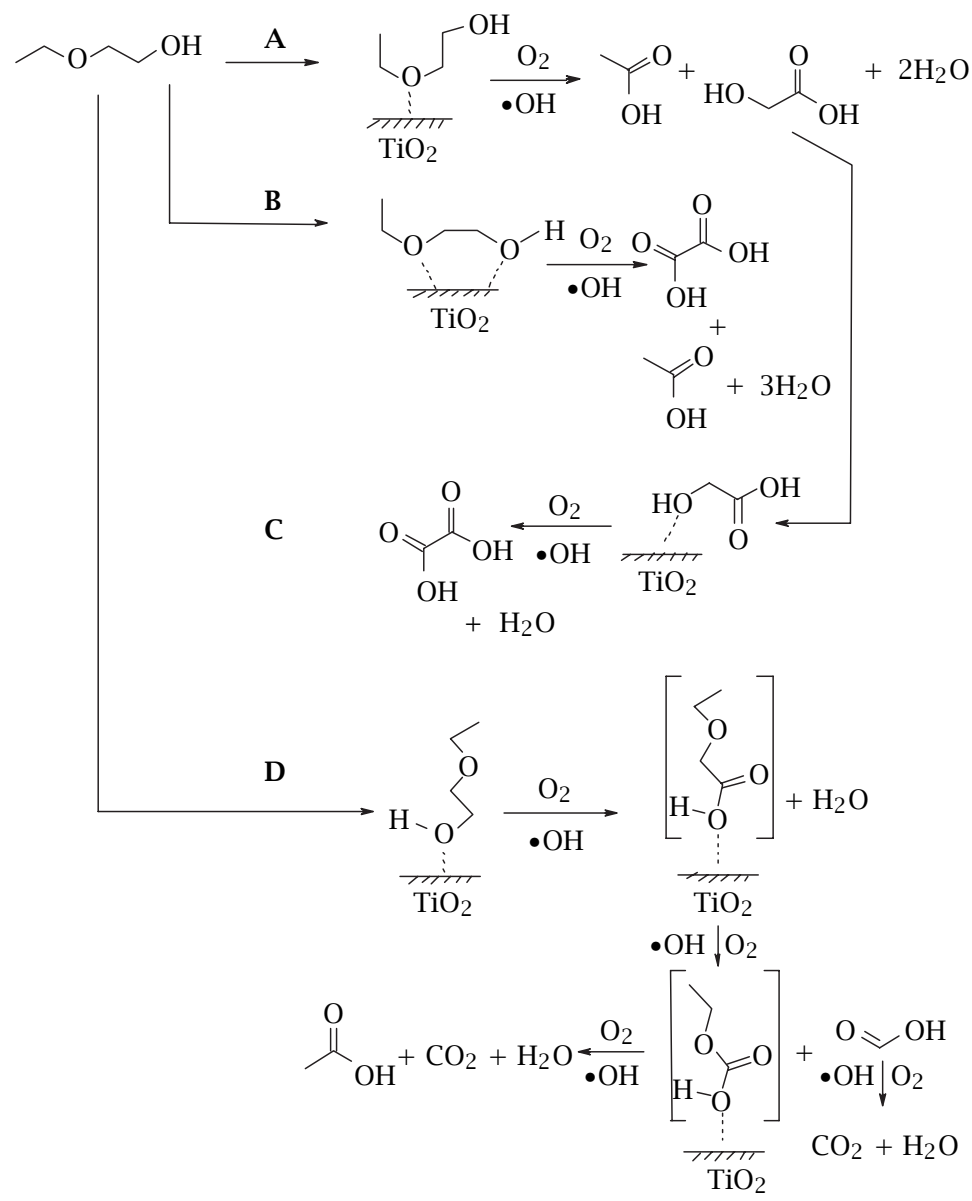

Figure 6. Outline of aqueous photocatalytic oxidation reaction of 2-ethoxy ethanol on $\mathrm{TiO}_{2}$.

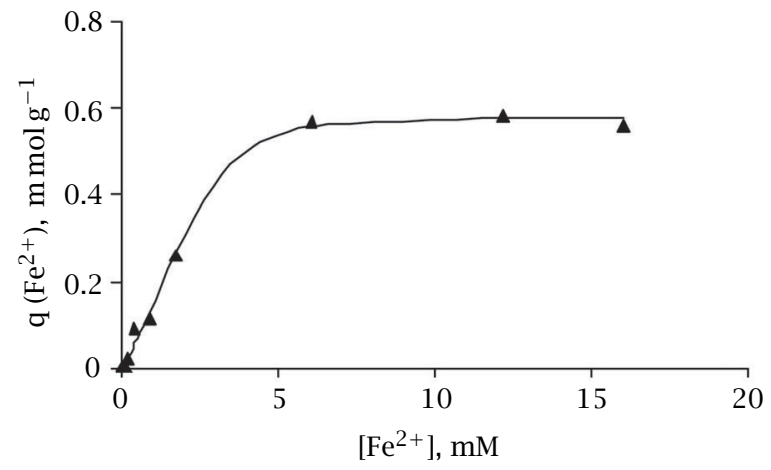

Figure 7. The surface concentration of $\mathrm{Fe}^{2+}$-ions on $\mathrm{TiO}_{2}$ versus $\mathrm{Fe}^{2+}$-ions equilibrium concentration at $\mathrm{pH} 3.0$ $\left(20^{\circ} \mathrm{C}\right)$.

suppressed in acidic media. The OH-radical, although less reactive with 2-EE, may also participate in oxidation reactions initiated by positively charged holes at the $\mathrm{TiO}_{2}$ surface.
The adsorption of ferrous/ferric ion on the surface of titanium dioxide was also studied. The results shown in Figure 7 are consistent with the adsorption equilibrium of MTBE: the equilibrium aqueous concentration of $\mathrm{Fe}^{2+}$ for the minimum adsorption of MTBE approximately coincides with the maximum adsorption of $\mathrm{Fe}^{2+}$, which shows a direct connection between the occupation of adsorption $\mathrm{TiO}_{2}$ sites with iron ions and the performance of PCO-the minimum PCO efficiency for MTBE was observed around this concentration of $\mathrm{Fe}^{2+}[9]$.

\section{CONCLUSIONS}

The complicated influence of the addition of multivalent metallic ions to aqueous solutions of groundwater pollutant, 2-ethoxy ethanol (2-EE), was studied. An optimum concentration range of ferrous ions was observed.

The hypothesis was supported that the optima are the result of a dual mechanism of oxidation at the surface of the $\mathrm{TiO}_{2}$ photocatalyst, including the direct 
oxidation of adsorbed pollutants with positively charged holes and the radical oxidation: the PCO of 2-EE resistant to radical oxidation practically stopped when the positively charged holes at the $\mathrm{TiO}_{2}$ surface were blocked by ferrous/ferric ions. The effective PCO of MTBE at high concentrations of $\mathrm{Fe}^{2+}$-ions observed in our previous work may be explained by the attack by hydroxyl radicals more efficient with MTBE.

\section{ACKNOWLEDGMENTS}

The authors express their gratitude to the Estonian Science Foundation (grant 5899), Centre for International Mobility (CIMO), Finland, and the Academy of Finland (Project 208134) for financial support.

\section{REFERENCES}

[1] N. Sax, Dangerous Properties of Industrial Materials, 6th ed., Van Nestrand Reinhold Co., New York, 1984, pp. 1343-1346.

[2] L. Nitschke, H. Wagner, G. Metzner, A. Wilk, and L. Huber, Wat. Res. 30 (1996), 644.

[3] A. Linsebigler, G. Lu, and J. Yates, Chem. Rev. 95 (1995), 735.

[4] V. Vamathevan, H. Tse, R. Amal, G. Low, and S. McEvoy, Catalysis Today 68 (2001), 201.

[5] J. Araña, O. González Díaz, J. Doña Rodríguez, J. Herrera Melian, C. Garriga i Cabo, J. Pérez Peña, M. Carmen Hidalgo, and J. Navío-Santos, J. Molecular Catalysis A: Chemical 197 (2003), 151.
[6] M. Mrowetz and E. Selli, J. Photochem. Photobiol. A: Chemistry 162 (2003), 89.

[7] V. Brezová, A. Blazková, E. Borosová, M. Čeppan, and R. Fiala, J. Molecular Catalysis A: Chemical 98 (1995), 109.

[8] D. Beydoun, H. Tse, R. Amal, G. Low, and S. McEvoy, J. Molecular Catalysis A: Chemical 177 (2002), 265.

[9] M. Krichevskaya, A. Kachina, T. Malygina, S. Preis, and J. Kallas, Int. J. Photoenergy 5 (2003), 81.

[10] N. Jackson, C. Wang, Z. Luo, J. Schwitzgebel, J. Ekerdt, J. Brock, and A. Heller, J. Electrochem. Soc. 138 (1991), 3660.

[11] E. Portjanskaja, M. Krichevskaya, S. Preis, and J. Kallas, Environ. Chem. Letters 2 (2004), 123.

[12] Standard Methods for the Examination of Water and Wastewater (L. Clesceri, A. Greenberg, and R. Trussel, eds.), 17th ed., APHA, AWWA, WPCF Washington, DC, 1989, pp. 3:102 and 5:15.

[13] R. Pohloudeck-Fabini and T. Beyrich, Organische Analyse, Akademische Verlagsgesellschaft Geest \& Portig K.-G, Leipzig, 1975, p. 145.

[14] C. Catastini, M. Sarakha, G. Mailhot, and M. Bolte, Sci. Total Environ. 298 (2002), 219.

[15] D. Bahnemann, Solar Energy 77 (2004), 445.

[16] N. Takahashi, Ozone: Sci. Eng. 12 (1990), 1.

[17] V. Brezová, Š. Vodný, M. Veselý, M. Čeppan, L. Lapčík, J. Photochem. Photobiol. A: Chemical 56 (1991), 125.

[18] S. Liang, L. Palencia, R. Yates, M. Davis, J.-M. Bruno, and R. Wolfe, J. Am. Wat. Works Assoc. 91 (1999), 11. 


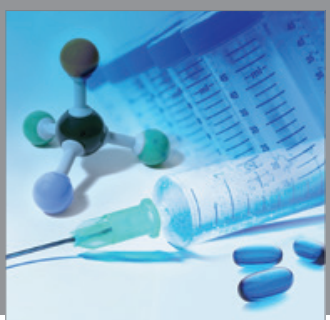

International Journal of

Medicinal Chemistry

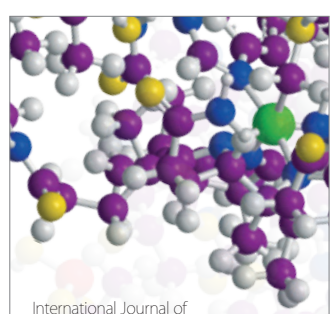

Carbohydrate Chemistry

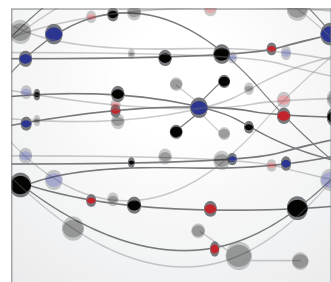

The Scientific World Journal
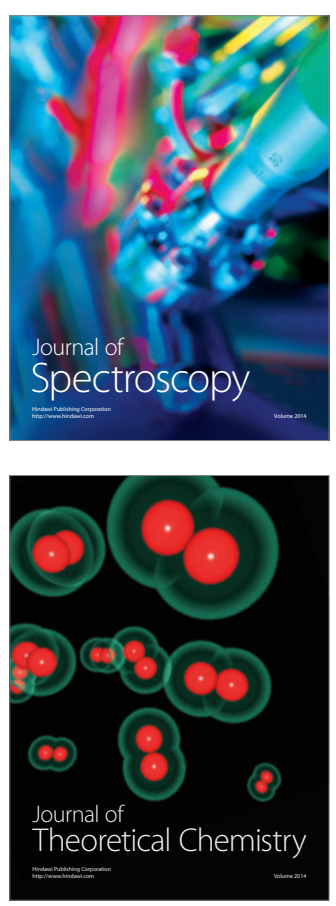
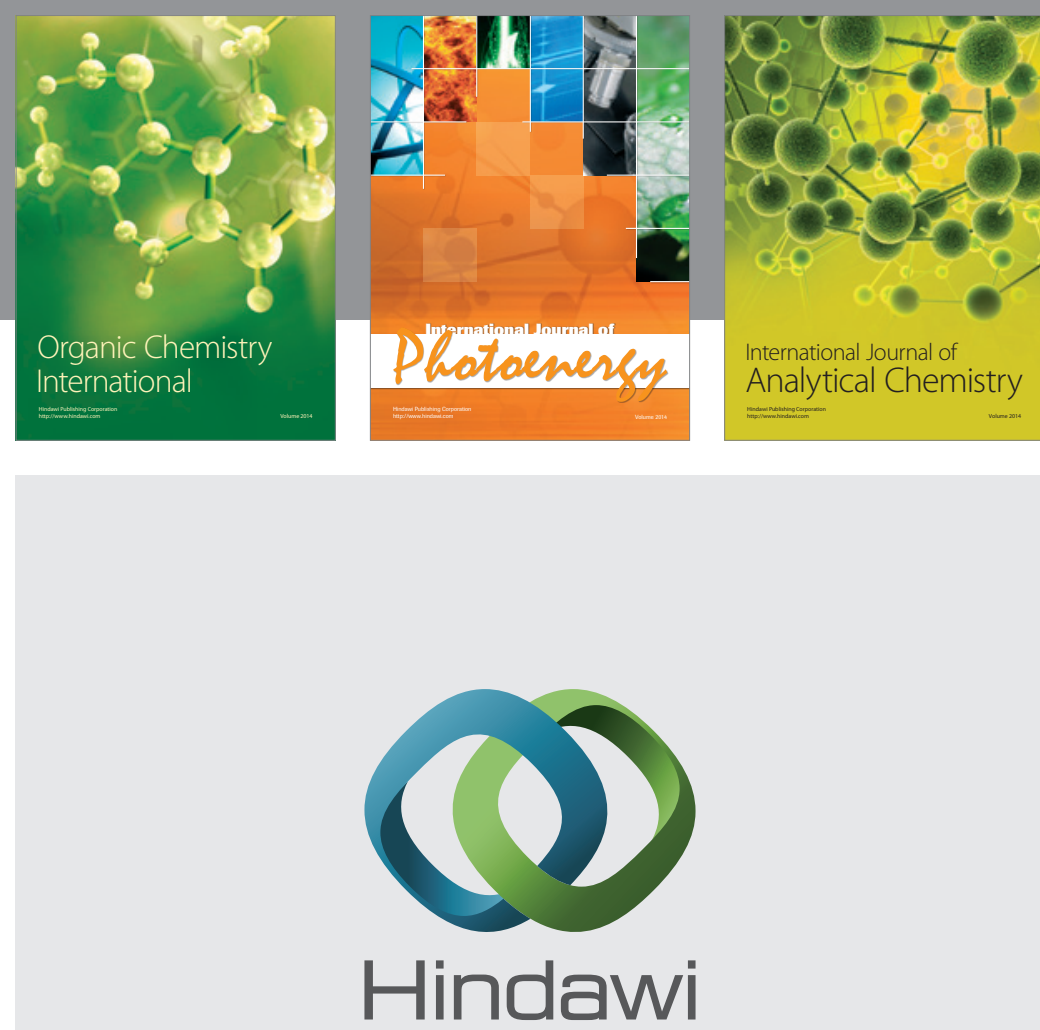

Submit your manuscripts at

http://www.hindawi.com
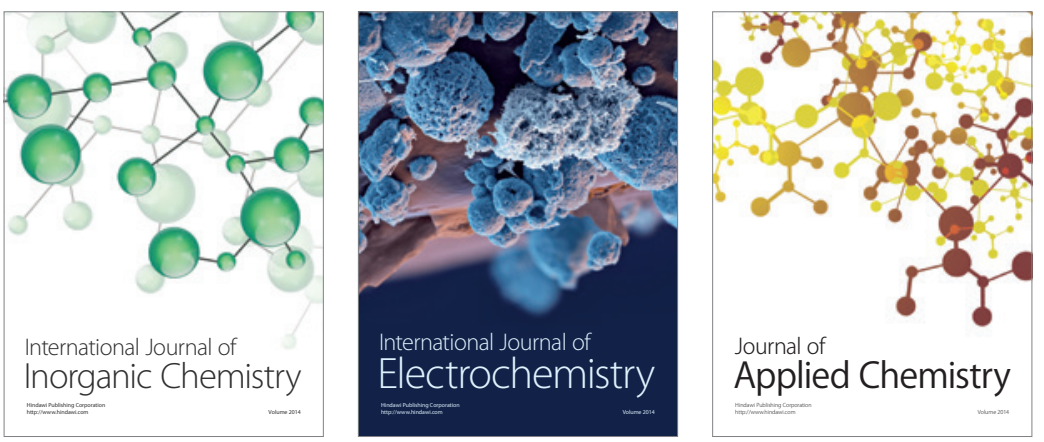

Journal of

Applied Chemistry
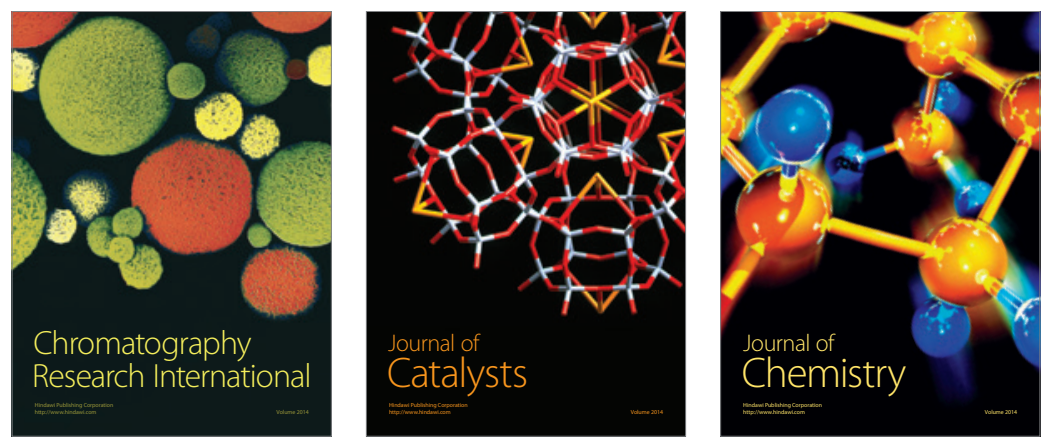
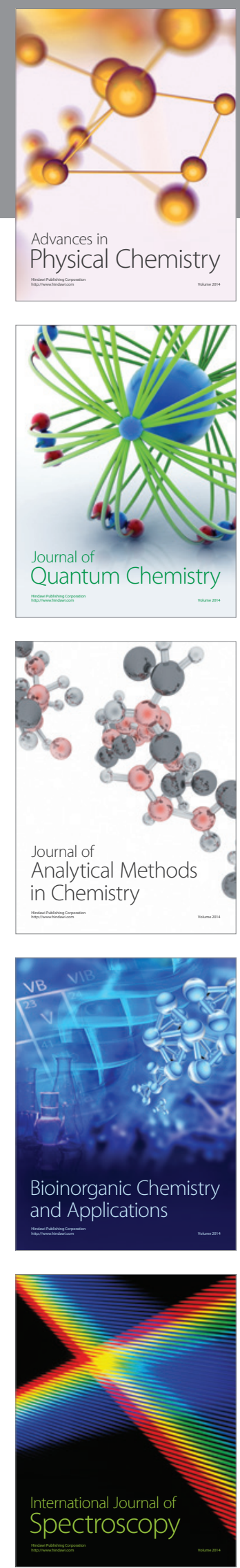